\title{
Offshore anchor piles under mooring forces: numerical modeling
}

Mohamed I. Ramadan, Stephen D. Butt, and R. Popescu

\begin{abstract}
A parametric study was carried out to study the behavior of offshore anchor piles under mooring forces in dense sand using a three dimensional (3-D) finite element model (FEM). The Mohr-Coulomb plastic model has been used to model the soil, and has been calibrated based on the centrifuge tests discussed in a Ph.D. thesis (published by Ramadan in 2011). The selection of model parameters and comparison of calibrated results with the centrifuge test results are discussed. In the parametric study, different pile lengths and diameters were considered to have different pile-soil rigidities. The pile was loaded at different load inclination angles to examine a wide range of loading conditions. From the current parametric study, design methods and design recommendations are given to help in improving the design of offshore anchor piles under monotonic mooring forces.
\end{abstract}

Key words: offshore anchor pile, dense sand, finite element model (FEM), inclined loading.

Résumé : Une étude paramétrique a été réalisée dans le but d'étudier le comportement de pieux d'ancrage en mer soumis aux forces d'ancrage dans un sable dense à l'aide d'un modèle par éléments finis (MEF) en trois dimensions (3D). Le modèle plastique de Mohr-Coulomb a été utilisé pour modéliser le sol. Le modèle a été calibré à partir des essais par centrifuge présentés dans une thèse de doctorat (publié par Ramadan en 2011). La sélection des paramètres du modèle et la comparaison des résultats calibrés avec les résultats des essais par centrifuge sont discutés. Dans l'étude paramétrique, les pieux avec des longueurs et diamètres différents sont considérés comme ayant des rigidités pieu-sol différentes. Le pieu a été soumis à des charges à différents angles d'inclinaison pour évaluer plusieurs conditions de chargement. Selon l'étude paramétrique présentée, des méthodes et des recommandations de conception sont suggérées afin d'aider à améliorer la conception de pieux d'ancrage en mer soumis à des forces monotoniques. [Traduit par la Rédaction]

Mots-clés : pieu d'ancrage en mer, sable dense, modèle par éléments finis (MEF), charge incline.

\section{Introduction}

The finite element method (FEM) has been widely used for geotechnical engineering applications. Many features developed in this method have made it easy to use. These features include coupled pore fluid elements for porous media, contact elements between two surfaces, and large deformation analysis. Also, one of the advantages of this method is the ability to use nonlinear elastoplastic models that can model the soil behavior under different loading conditions.

In this paper, the scope of centrifuge test results done by Ramadan (2011) is extended by means of a parametric study using the FEM. A three dimensional (3-D) FEM has been established to study the soilpile interaction behavior under mooring forces. Numerical analysis was carried out using ABAQUS 6.7 finite element analysis program (Hibbitt, Karlsson, and Sorenson, Inc. 1998). The Mohr-Coulomb plastic model has been used to model the soil, and has been calibrated based on the centrifuge tests of Ramadan (2011). In the first part of this paper, the selection of the model parameters and comparison of calibrated results with the centrifuge test results will be discussed. In the second part, the calibrated FEM will be used to perform a parametric study. In the current parametric study, only pile geometry and loading conditions were changed. Soil properties were the same as those for dense sand used in the FEM calibration. Different pile lengths and diameters were considered to have different pile-soil rigidities. The pile was loaded at different load inclination angles $(\theta)$ to examine a wide range of loading conditions. Figure 1 shows a sketch of the problem under study.

\section{Finite element model calibration}

A 3-D FEM was established to study the behavior of offshore anchor piles subjected to mooring forces, which was calibrated using the centrifuge tests discussed in the previous section. The commercial finite element analysis program ABAQUS 6.7 (Hibbitt, Karlsson, and Sorenson, Inc. 1998) was used in the analysis. The first step in this analysis was the geostatic step for the soil, to apply soil gravity. In the next step, the pile and the contact elements were activated and a prescribed displacement was applied at the top side node of the pile at the symmetry plane. The prescribed displacement had been applied with different angles $(\theta)$ to horizontal at the ground surface (no eccentricity; $e=0$ ).

In this section the FEM geometry, meshing, and constitutive models of the pile and the soil will be discussed. The calibrated results will be compared with the centrifuge tests results.

\section{Model geometry and meshing}

Figure 2 shows the geometry of the FEM. Due to the symmetric loading condition only a half-cylinder representing the soil and the pile was considered. The soil boundaries extend horizontally 30 times the pile diameter, while below the pile tip the soil extends 10 times the pile diameter, as recommended by Achmus et al. (2009). The model boundary at the bottom is restrained from displacement in all directions. The side boundary is restrained from horizontal displacement. At the symmetry plane, the boundary is restrained from displacement in the perpendicular direction. The top of the model is free to move. 
Fig. 1. Problem under study: pile subjected to mooring force. $d$, pile diameter; $e$, eccentricity; $F$, mooring force; $L$, pile length.

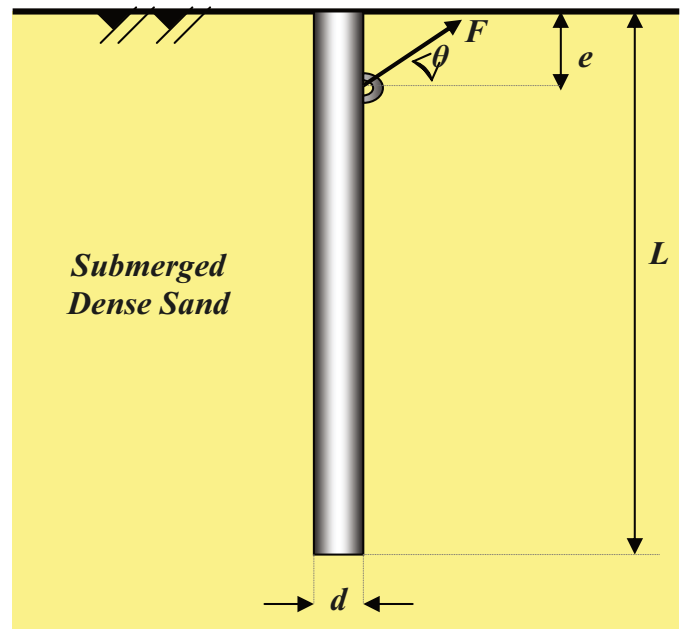

Fig. 2. Finite element model meshing and boundary conditions.

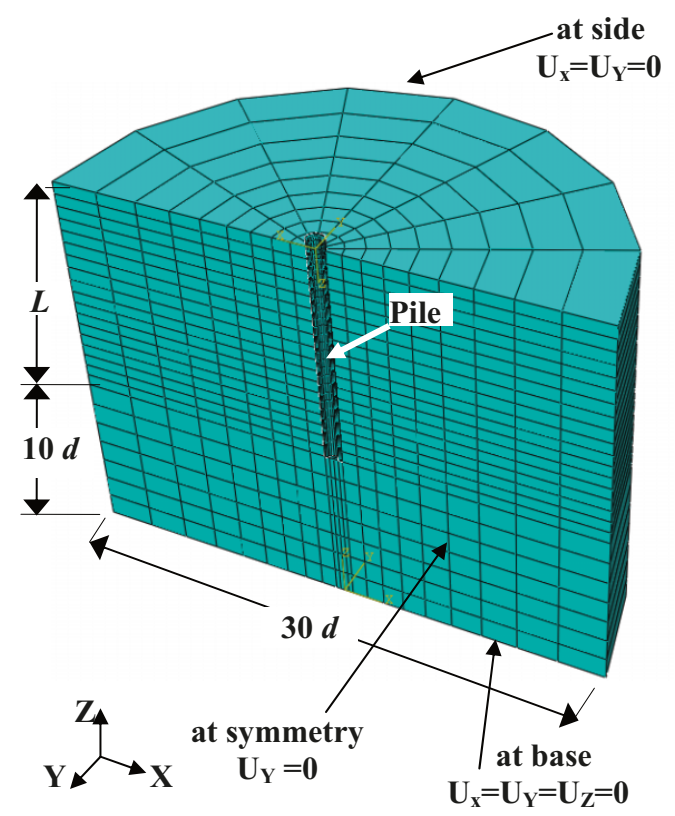

The finite element mesh used in the analysis is shown in Fig. 2. The elements used are eight-node continuum elements with porous properties for those elements modeling the soil. The elements are biased towards the pile to have finer mesh close to the pile where the stresses are expected to be higher. The mesh is coarser farther from the pile to reduce the analysis processing time. A finer mesh close to the pile was used to check the mesh refinement effect on the results. Both the lateral load - lateral displacement at the pile head curves were found to be within less than $5 \%$ difference.

The pile is modeled as a pipe pile as in the centrifuge test. To have both the flexural and axial stiffnesses the same as in the centrifuge test in prototype scale, the pile wall thickness and Young's modulus of the pile material were recalculated based on the centrifuge modeling scaling laws. Pile section dimensions and material properties are given in Table 1.

\section{Constitutive models}

Two constitutive models have been used to model both the pile and soil. Both models will be discussed.
Table 1. Pile section properties for the FEM.

\begin{tabular}{lll}
\hline Characteristic & Prototype $(70 g)$ & Prototype $(50 g)$ \\
\hline External diameter, $d(\mathrm{~m})$ & 1.4 & 1.0 \\
Wall thickness, $t(\mathrm{~m})$ & 0.2725 & 0.195 \\
Young's modulus, $E_{\mathrm{p}}(\mathrm{MPa})$ & 27609 & 27592 \\
\hline
\end{tabular}

\section{Pile modeling}

The pile material is assumed to be linear elastic. This assumption is valid as the pile did not reach the yield bending moment during the centrifuge tests. The linear elastic material is defined by the elastic Young's modulus of the pile material $\left(E_{\mathrm{p}}\right)$ and Poisson's ratio $\left(\nu_{\mathrm{p}}\right)$. Offshore anchor piles are usually made of steel. The Young's modulus of steel is $2.1 \times 10^{8} \mathrm{kN} / \mathrm{m}^{2}$ and the Poisson's ratio $\left(\nu_{\mathrm{p}}\right)$ of steel is about 0.3 (De Nicola and Randolph 1993). However, to simulate both the flexural and axial stiffnesses of the pile in the centrifuge tests, an equivalent Young's modulus had been calculated. The values of $E$ and $\nu$ used in the analysis are given in Table 1.

\section{Soil modeling}

Sand is assumed to behave as an elastic, perfectly plastic material obeying the Mohr-Coulomb failure criterion. Mohr-Coulomb model parameters that are needed to calibrate the model are the effective unit weight of the soil, $\gamma^{\prime}$; soil Young's modulus, $E_{\mathrm{s}}$; soil Poisson's ratio, $\nu$; effective angle of internal friction, $\phi^{\prime}$; dilation angle, $\psi$; and effective cohesion, $c^{\prime}$. These parameters were calculated using some available correlations of the cone penetration tests (CPTs) carried out during the centrifuge test.

Young's modulus of the sand was calculated using the correlation suggested by Schmertmann (1978) and Robertson and Campanella (1983). Ferguson and Ko (1984) performed a series of centrifuge tests to examine the application of the cone penetration test in sand in a centrifuge. They concluded that Schmertmann's (1978) correlation is reasonably conservative for their centrifuge tests. Schmertmann (1978) related the constrained modulus $(C)$ directly to the measured cone tip resistance $\left(q_{c}\right)$, particularly in fine sandy soils

$$
C=\alpha q_{\mathrm{c}}
$$

where $\alpha$ is a dimensionless factor ranging between 3 and 9 as recommended by Baldi et al. (1982). In the present calibration a value of 5 was found to have a good match with the centrifuge results.

In the current soil model, the Young's modulus was assumed to be increasing linearly by depth corresponding to the following equation:

[2] $\quad E_{\mathrm{s}}=\frac{(1+\nu)(1-2 \nu)}{(1-\nu)} C$

Bolton (1986) reviewed extensive laboratory data on sands and developed a simplified relationship between relative density, effective mean stress $\left(p^{\prime}\right)$, and peak friction angle $\left(\phi^{\prime}\right)$. He introduced a new relative dilatancy index $\left(I_{R}\right)$ of the form

$$
I_{\mathrm{R}}=D_{\mathrm{r}}\left[10-\ln \left(p^{\prime}\right)\right]-1
$$

where $D_{\mathrm{r}}$ is the relative density of the sand.

He also correlated the peak friction angle $\left(\phi^{\prime}\right)$ and the critical state friction angle $\left(\phi_{c}^{\prime}\right)$ to $I_{R}$

[4] $\quad \phi^{\prime}-\phi_{\mathrm{c}}^{\prime}=3 I_{\mathrm{R}}$ 
To use Bolton's method to calculate the peak friction angle ( ') profile, both sand relative density $\left(D_{\mathrm{r}}\right)$ and the critical state friction angle ( $\left.\begin{array}{c}c \\ c\end{array}\right)$ are needed. Vaid et al. (2001) reported a value of $34^{\circ}$ for the critical state friction angle ( $\left.\begin{array}{c}\text { c} \\ c\end{array}\right)$ of Fraser River sand. To obtain the relative density, density cubes were used during sample preparation for the centrifuge tests. The relative density was changing from $88 \%$ at the bottom of the model to about $84 \%$ at the top of the model. Bolton and Gui (1993) correlated the normalized cone tip resistance $(Q)$ to relative density $\left(D_{r}\right.$, in \%) from a series of centrifuge tests as

$$
D_{\mathrm{r}}=0.2831 Q+32.964
$$

where $Q=\left(q_{\mathrm{c}}-\sigma_{\mathrm{v}}\right) / \sigma_{\mathrm{v}}^{\prime}$ and $\sigma_{\mathrm{v}}$ and $\sigma_{\mathrm{v}}^{\prime}$ are the total and effective stresses of sand, respectively.

Figure 3 shows the calculated sand relative density profile using eq. [5]. The calculated peak friction angle of sand using eq. [4] for the $70 \mathrm{~g}$ centrifuge test is plotted in Fig. 4. At deep depths, the eq. [4] suggests a peak friction angle ranging between $43^{\circ}$ and $44^{\circ}$. Chakrabortty (2008) suggested a value of $43^{\circ}$ for Fraser River sand at a relative density of $80 \%$. However, it can be seen that there is an obvious reduction in the relative density at shallow depths less than 80 and $60 \mathrm{~mm}$ (in centrifuge model scale) for $50 \mathrm{~g}$ and $70 \mathrm{~g}$ tests, respectively. This underestimation at low confining stresses using the CPT method has been observed by many authors (Bolton and Gui 1993; Puech and Foray 2002; Robertson 2010: and others). At shallow penetrations in sand (less than $3 \mathrm{~m}$ in prototype scale), the increase of the cone resistance with depth is strongly affected by the low confining pressures (Puech and Foray 2002). Figure 3 shows that this underestimation in both $50 \mathrm{~g}$ and $70 \mathrm{~g}$ tests happens at a vertical effective stress of $40 \mathrm{kPa}$, which is the same as recommended by Puech and Foray (2002). To correct this underestimation, the relative density for vertical effective stresses at $40 \mathrm{kPa}$ was taken as a constant value for all vertical effective stresses less than $40 \mathrm{kPa}$. The peak friction angle profile calculated using the modified relative density profile is shown in Fig. 4. It can be seen that the peak friction angle using this modified relative density increases rapidly when depth or confining stress is decreasing. This behavior has been observed by many researchers (Turner and Kulhawy 1994; Zhu 1998; Lancelot et al. 2006).

A comparison between the present method and that given by Zhu (1998) is shown in Fig. 4. There is a good agreement between both methods. The high value of the internal friction angle of dense sand at shallow depth (low confining stress) was also observed (i) offshore at the Grand Bank as reported by Thompson and Long (1989) and (ii) by Lancelot et al. (2006) in dense sand for Hostun sand at low confining stresses. It can be concluded that these high values of internal friction angle can be observed for angular to subangular dense sand, which is the case for Fraser River sand used in the present centrifuge study.

The sand dilation angle was calculated using the equation suggested by Bolton (1986)

$$
\psi=\frac{{ }^{\prime}-{ }^{\prime}}{0.8}
$$

\section{Soil-pile interaction}

A basic Coulomb frictional model was used to govern the interaction between the pile and sand surfaces (Hibbitt, Karlsson, and Sorensen, Inc. 1998).

The contact surface approach implemented in ABAQUS allowed for separation and sliding of finite amplitude and arbitrary rotation of the contact surface. When surfaces are in contact, they usually transmit shear as well as normal forces across their inter-
Fig. 3. Sand relative density profile along depth using eq. [5].

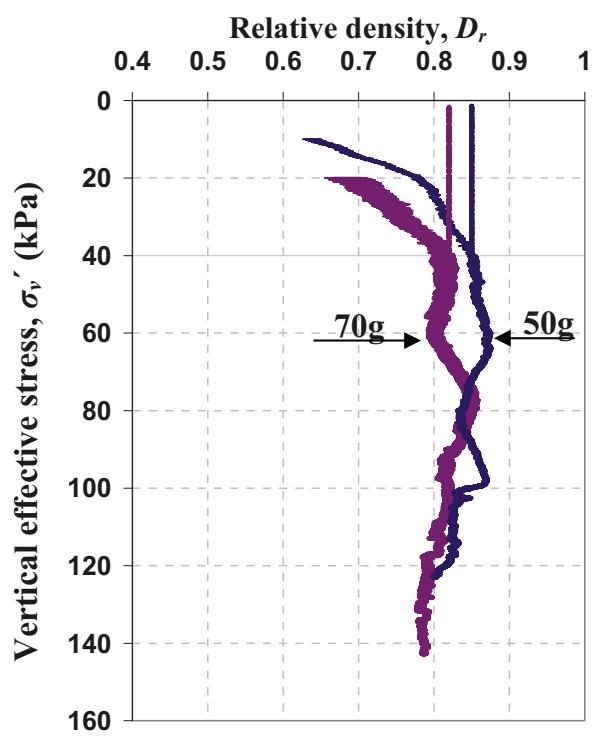

Fig. 4. Sand friction angle profile along depth using the modified relative density and Zhu (1998).

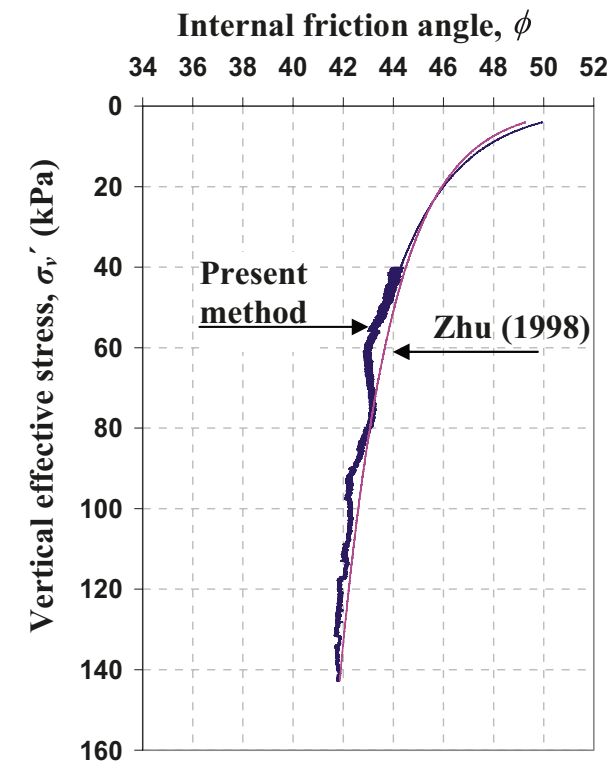

face. There is generally a relationship usually expressed in terms of the stresses at the interface of bodies

[7] $\tau=\mu \sigma_{\mathrm{h}}$

where $\tau$ is the shear stress on the contact surface, $\mu$ is the friction coefficient $(=\tan \delta$; where $\delta$ is the interface angle between the sand and pile), and $\sigma_{\mathrm{h}}$ is the normal stress on the contact surface. It was assumed that the soil and pile are both deformable bodies and can undergo finite relative sliding.

For the centrifuge tests in the current study, the pile was coated with an epoxy layer. The epoxy layer provided a smooth surface for the pile surface. De Nicola and Randolph (1999) used model piles coated with epoxy in a centrifuge. They recommended a value of 0.53 for the friction coefficient between the epoxy surface and sand. In the FEM analysis a value of 0.55 was assumed along the soil-pile interface. 


\section{Modeling pile installation effect}

The pile installation method has a major effect on the pile loading behavior. For offshore driven piles, as discussed previously, the lateral stresses will increase in the soil in a limited zone adjacent to the pile. The lateral earth pressure coefficient, $K$, after pile installation was calculated based on the Imperial College pile (ICP) 2005 method (Jardine et al. 2005). The soil model was divided into horizontal layers. The lateral earth pressure coefficient $(K)$ values were assigned to each layer. Although the increase in the lateral stress should be confined to a limited zone around the pile, it has been found, to simplify the model and due to the analysis convergence, that increasing the lateral stress along the full width of the soil model has minimal effect on the results as the main increase in the lateral stresses is concentrated to the pile tip vicinity, which will have a negligible movement for a flexible pile. Table 2 summarizes the input parameters used in the FEM validation.

\section{FEM output computations}

Bending moment of the pile was computed at the outermost nodes of the pile in the loading direction. Equation [8] was used to calculate bending moment $(M)$

[8] $\quad M=\frac{2 \sigma_{\mathrm{b}} I_{\mathrm{p}}}{d}$

where $\sigma_{\mathrm{b}}=\left(\sigma_{1}-\sigma_{2}\right) / 2\left(\sigma_{1}\right.$ and $\sigma_{2}$ are axial stress at the same depth at the tension and compression sides of the pile, respectively), $I_{\mathrm{p}}$ is the moment of inertia of the pile cross section, and $d$ is pile diameter.

Soil pressure was obtained from ABAQUS as the contact pressure at the contact surface between the pile and soil. The pile deflection profile was obtained directly at pile nodes along the pile.

\section{FEM calibration results}

In this section a comparison between the centrifuge tests results and the FEM will be presented for the following cases: $(i)$ pure tension loading, (ii) pure lateral loading, and (iii) inclined pullout loading for loading angles $(\theta)$ of $16^{\circ}$ and $30^{\circ}$ to horizontal.

\section{Pure tension loading}

Figure 5 shows the vertical load $(V)$ - normalized vertical displacement $(v / d)$ relationship at the pile head for the test at $50 \mathrm{~g}$. For the tension loading case, the $70 \mathrm{~g}$ test was not simulated using FEM as the calculated $K$ profile from the centrifuge test was very high, which caused convergence problems. It can be seen that there is good agreement between FEM and the centrifuge test result in terms of the ultimate tension capacity and the initial stiffness. In the centrifuge test, the stiffness increased before reaching ultimate capacity. This increase could be due to a soil dilation effect with the small-scale pile as will, be discussed later in the inclined loading case.

\section{Pure lateral loading}

Figure 6 shows the lateral load $(H)$ - lateral deflection $(u)$ relationship comparing both the centrifuge test and FEM for centrifuge tests. There is good agreement between the centrifuge test and the predicted results using FEM, which predicts the initial stiffness the same as that in the centrifuge tests. FEM predicts the bending moment profile $(M)$ in good agreement, especially the maximum bending moment values and their depths as shown in Fig. $7 a$.

Soil pressure distribution along the pile $(P)$ at different load increments is shown in Fig. 7b. FEM predicts well the soil pressure at shallow depths at small load increments. However, by increasing the lateral load at the pile head, FEM underpredicts the maximum soil pressure. This underprediction is due to the perfectly
Table 2. Soil input parameters in the FEM.

\begin{tabular}{ll}
\hline Characteristic & Value \\
\hline Sand Young's modulus, $E\left(\mathrm{MN} / \mathrm{m}^{2}\right)$ & $3.7 q_{\mathrm{c}}$ \\
Sand effective friction angle, ${ }^{\circ}\left({ }^{\circ}\right)$ & $52-42$ (Fig. 4) \\
Sand dilation angle, $y\left(^{\circ}\right)$ & $22.5-10$ (eq. [6]) \\
Soil-pile friction coefficient, & 0.55 \\
Lateral earth pressure coefficient, $K$ & Using ICP 2005 \\
& (Jardine et al. 2005) \\
\hline
\end{tabular}

Fig. 5. Vertical load $(V)$ versus normalized vertical displacement $(v / d)$ relationship.

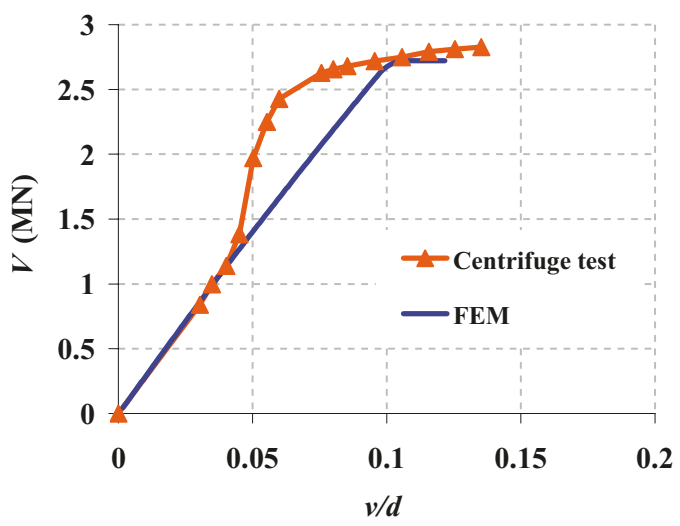

Fig. 6. Lateral load $(H)$ versus lateral deflection $(u)$ relationship at pile head.

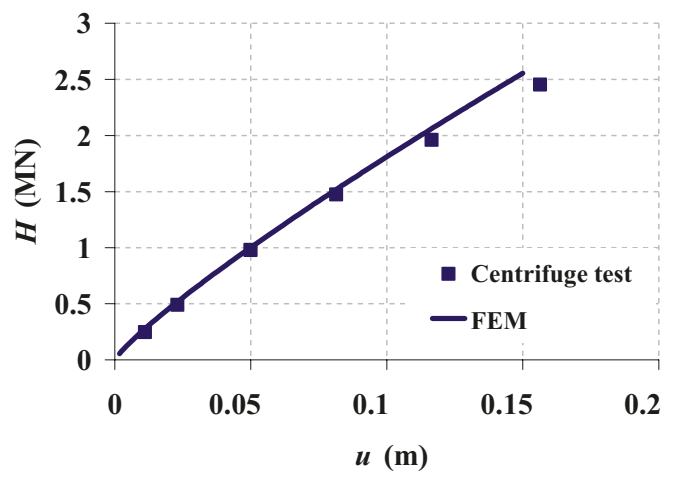

plastic behavior of the Mohr-Coulomb soil model. If soil hardening were to be allowed in the soil model, results could be improved.

For the pile lateral deflection profile $(u)$, FEM gives good prediction above the rotation point observed in the centrifuge tests results as shown in Fig. $7 c$. The FEM profile shows a flexible pile behavior in contrast to a rigid pile behavior observed in the centrifuge tests. According to Broms (1964) and Meyerhof (1995), the pile-soil rigidity in the present test should be flexible. This is supported by the FEM results. In the centrifuge tests, the high confining pressure close to pile tip due to pile driving might cause small errors in strain gauge readings. This will lead to errors in the integrated pile deflection values close to pile tip. Also, the pile lateral deflection profile in the centrifuge tests was calculated using the measured rotation and lateral displacement at the pile head. Dyson and Randolph (2001) reported that using pile head rotation provided some redundancy. They assumed zero displacement at the pile tip, and in their centrifuge test the pile was highly flexible. However, in the current centrifuge tests (Ramadan 2011), the pile is of low flexibility and the assumption of zero displace- 
Fig. 7. Pure lateral loading case (FEM curve is a solid line): (a) bending moment, (b) soil pressure, and (c) pile lateral deflection.

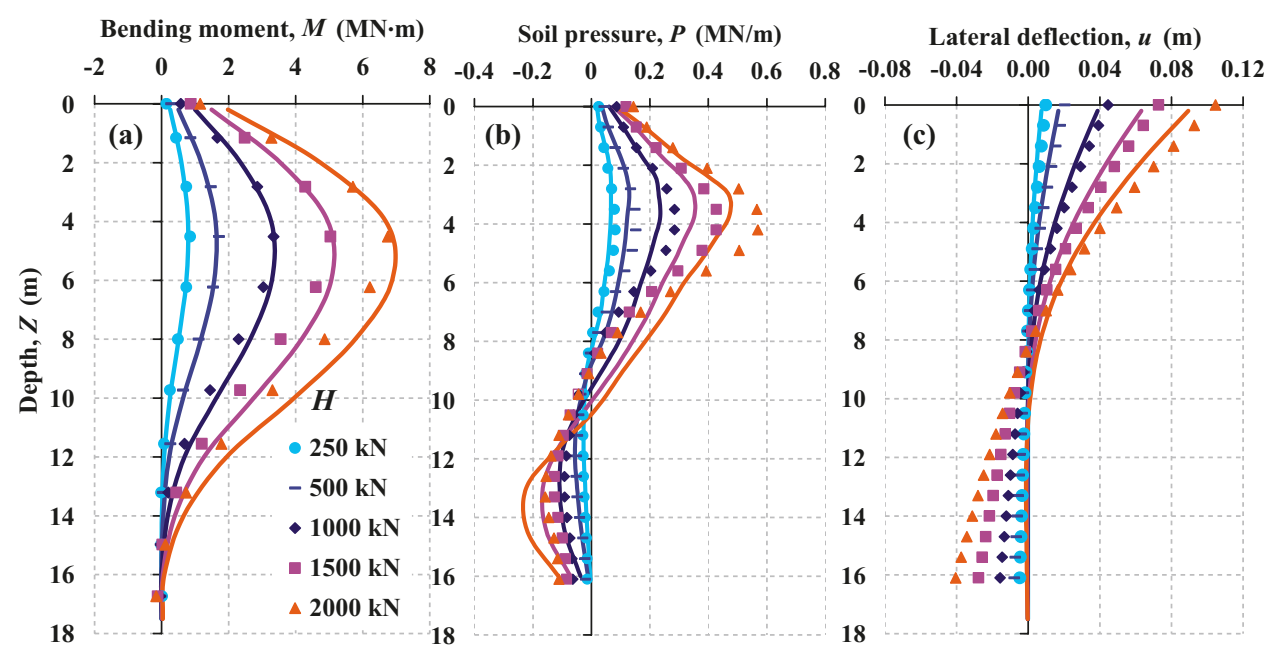

ment at the pile tip is not valid. For these reasons, there is a difference between pile deflection close to the pile tip in both FEM and centrifuge results.

For design purposes, load-displacement curves and maximum bending moments are used. It can be seen that FEM predicts well the load-displacement curve (Fig. 6). The relations between the normalized horizontal load $\left(H_{n}\right)$ on the pile head and the normalized maximum bending moment $\left(M_{n-m a x}\right)$ for all piles are shown in Fig. 8. Both $H_{\mathrm{n}}$ and $M_{\mathrm{n}-\mathrm{max}}$ can be defined as follows:

$$
\begin{aligned}
& {[9 a] \quad H_{\mathrm{n}}=\frac{H}{\gamma^{\prime} d^{3}}} \\
& {[9 b] \quad M_{n-\max }=\frac{M_{\max }}{\gamma^{\prime} d^{4}}}
\end{aligned}
$$

where $H$ is the horizontal load at the pile head, $M_{\max }$ is the maximum bending moment, $\gamma^{\prime}$ is the effective unit weight of sand, and $d$ is pile diameter.

Maximum bending moment $\left(M_{\mathrm{n}-\max }\right)$ values predicted by FEM are in a very good agreement with the centrifuge test results as shown in Fig. 8. It can be concluded that FEM can simulate the behavior of laterally loaded piles with good agreement.

\section{Inclined pullout loading}

The total load $(F)$ - total displacement $(w)$ relationship is shown in Fig. 9. The FEM results show the same initial stiffness as the centrifuge test results for both tests at loading angles $(\theta)$ of $16^{\circ}$ and $30^{\circ}$ to horizontal. At higher deflection, FEM at a loading angle of $16^{\circ}$ shows a stiffer response than the centrifuge test. However, both FEM and centrifuge test results show stiffer pile response when increasing $\theta$.

The comparison is extended to the bending moment profile $(M)$, soil pressure distribution $(P)$, and pile lateral deflection profile $(u)$ as shown in Fig. 10. FEM predicts soil pressure at shallow depths and pile deflection above the rotation point in good agreement. There is an overprediction in the bending moment profile. This overprediction is more than in the case of pure lateral loading. Figure 8 shows the relationship between $H_{n}$ and $M_{n-m a x}$, where it can be seen that all the centrifuge tests have a constant slope regardless of the loading angle. This is also the same observation for FEM although it has a higher slope than that of the centrifuge tests. This means that FEM supports the notion that $M_{n-m a x}$ does not change when the loading angle changes. The difference in the slope between both the FEM and centrifuge tests results could be due to soil dilation. At a small vertical pullout load component,
Fig. 8. Normalized horizontal load $\left(H_{n}\right)$ versus normalized maximum bending moment $\left(M_{n-\max }\right)$.

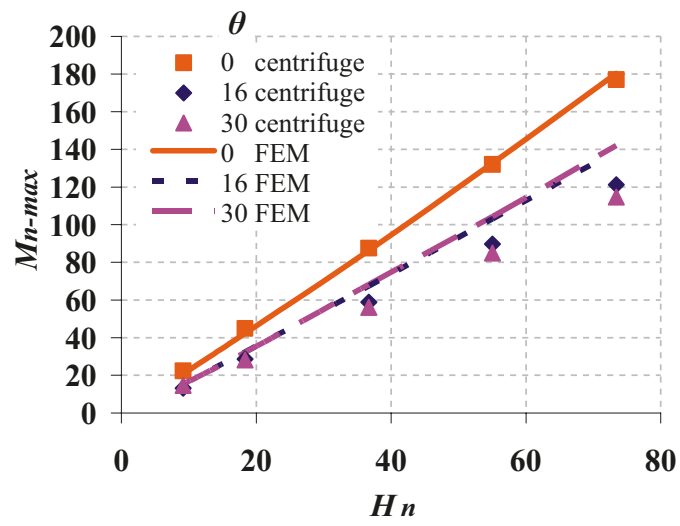

Fig. 9. Total load $(F)$ versus total displacement $(w)$ relationship at pile head.

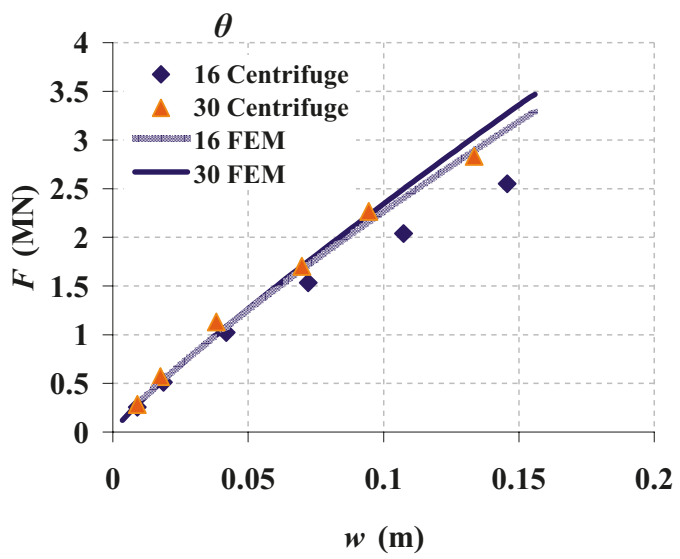

FEM results are very close to the centrifuge tests results. By increasing the vertical pullout load component, soil dilation increases. This increase in soil dilation causes a decrease in pile bending moment. The effect of dilation is higher in the case of the small-scale model pile, as in the centrifuge test cases. However, for large-diameter piles (larger than $1 \mathrm{~m}$ ), the effect of soil dilation is small, as reported by Jardine et al. (2005). This large diameter case interprets the deviation of the FEM results from the centri- 
Fig. 10. Inclined lateral loading case of $\theta=30^{\circ}$ (FEM curve is a solid line): (a) bending moment, (b) soil pressure, and (c) pile lateral deflection.

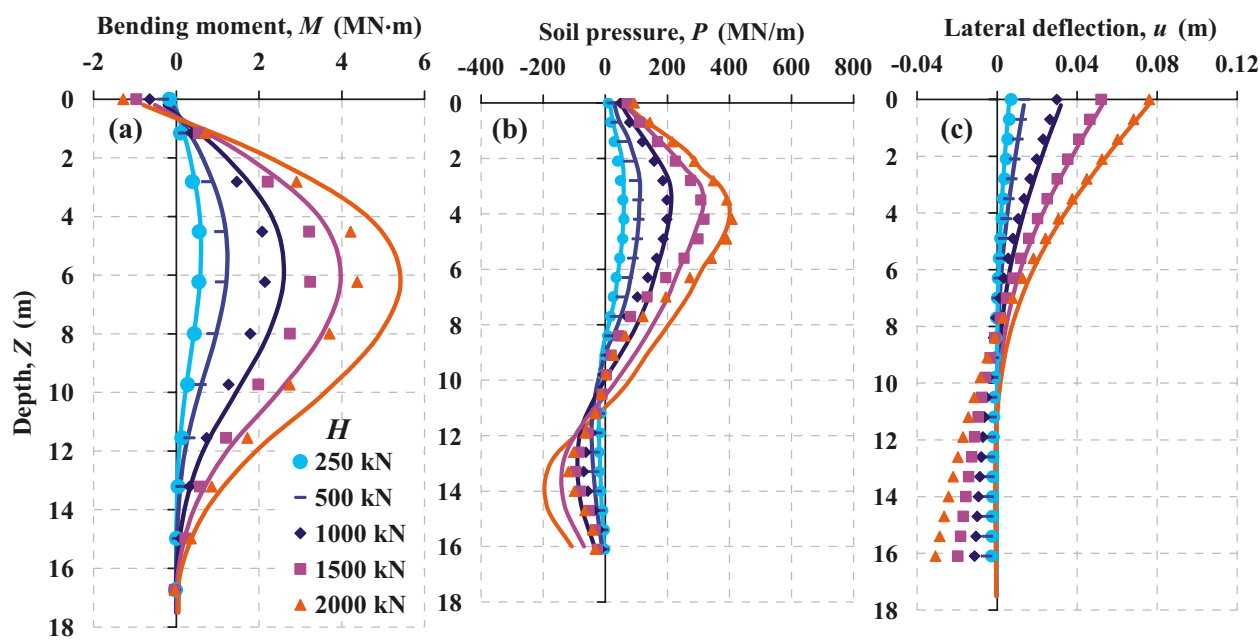

fuge tests results by increasing the load at the pile head, which was not observed in the case of pure lateral loading.

From the previous comparison between FEM and centrifuge test results, it can be concluded that FEM is capable of simulating the behavior of offshore anchor piles under mooring forces. There is good agreement between FEM and centrifuge test results. In the next section, the calibrated FEM will be used to perform a parametric study.

\section{Parametric study}

The parametric study was carried out by changing pile geometry. Both pile diameter and length were considered to have different pile-soil rigidities. In all cases the pile was loaded at the ground surface (no eccentricity; $e=0$ ) at loading inclination angles $\theta=0^{\circ}, 5^{\circ}, 10^{\circ}, 15^{\circ}, 30^{\circ}, 60^{\circ}$, and $90^{\circ}$ to horizontal. Although offshore anchor piles are usually subjected to mooring forces with maximum loading angles of about $30^{\circ}$, as reported by Randolph et al. (2005), higher loading angles were examined in the present study to understand the effect of the interaction between vertical and horizontal pullout loading on offshore anchor pile behavior. The parameter combinations used in the parametric study are shown in Table 3 . All piles have the same wall thickness $(t)$ of $30 \mathrm{~mm}$ (to have a ratio of $d / t$ ranging from 33.3 to 66.7 that is being used for offshore piles) and a Young's modulus of steel $2.1 \times 10^{8} \mathrm{kN} / \mathrm{m}^{2}$.

Pile-soil flexibility was calculated as the ratio of pile length $(L)$ to the elastic length (T). The elastic length was calculated using eq. [10], as given by Broms (1964), as follows:

$$
T=\sqrt[5]{\frac{E_{\mathrm{p}} I_{\mathrm{p}}}{n_{\mathrm{h}}}}
$$

where $n_{\mathrm{h}}$ is the constant of horizontal subgrade reaction $\left(\mathrm{FL}^{-3}\right.$ dimensions), given $k_{\mathrm{h}}$, which is the subgrade reaction modulus ( $=n_{\mathrm{h}} Z$ ( $\mathrm{FL}^{-2}$ dimensions) where $\mathrm{Z}$ is depth).

In eq. [10], the parameter $n_{\mathrm{h}}$ was assumed as $40 \mathrm{MN} / \mathrm{m}^{3}$ as recommended by API (2000) for dense sand.

A total of 56 runs were carried out in the current parametric study. All piles were loaded at the ground surface with no eccentricity (e) using displacement control and under drained conditions. For some cases, the pile was pulled out to a large displacement to get the ultimate capacity of the pile. In all cases, the pile was loaded within the elastic range. In the next sections, the results of the parametric study will be discussed. The soil-pile interaction will be discussed in terms of pile bending moment profile, soil pressure along the pile,
Table 3. Parameters of the parametric study.

\begin{tabular}{lllllll}
\hline $\begin{array}{l}\text { Case } \\
\text { No. }\end{array}$ & $\begin{array}{l}\text { Diameter, } \\
d(\mathrm{~m})\end{array}$ & $\begin{array}{l}\text { Length, } \\
L(\mathrm{~m})\end{array}$ & $L / d$ & $\begin{array}{l}\mathrm{E}_{\mathrm{p}} \mathrm{I}_{\mathrm{p}} \\
\left(\mathrm{MN} \cdot \mathrm{m}^{2}\right)\end{array}$ & $\mathrm{T}(\mathrm{m})$ & $L / T$ \\
\hline 1 & 2 & 8 & 4 & 18919 & 3.43 & 2.33 \\
2 & 2 & 12.5 & 6.25 & 18919 & 3.43 & 3.65 \\
3 & 2 & 15 & 7.5 & 18919 & 3.43 & 4.38 \\
4 & 2 & 17.5 & 8.75 & 18919 & 3.43 & 5.1 \\
5 & 1 & 12.5 & 12.5 & 2260 & 2.24 & 5.58 \\
6 & 1.4 & 17.5 & 12.5 & 6365 & 2.76 & 6.35 \\
7 & 2 & 25 & 12.5 & 18919 & 3.43 & 7.3 \\
8 & 2 & 35 & 17.5 & 18919 & 3.43 & 10.2 \\
\hline
\end{tabular}

soil shear stress along the pile, and pile deflection profile. Design methods will be suggested to predict pile ultimate capacity and maximum bending moment.

\section{Load-displacement relationships}

Figure 11 shows load-displacement relationship at pile head for case 4 . The figure shows the horizontal load $(H)$ versus horizontal deflection $(u)$ relationship, vertical load $(V)$ versus vertical displacement $(v)$ relationship, and total load $(F)$ versus total displacement $(w)$ relationship. The analysis was carried out for piles of a wide range of flexibilities $(L / T)$. There is a significant interaction between lateral and vertical pullout loading conditions. The lateral load component is affected by the vertical pullout loading. The vertical pullout load component increases the initial stiffness of the $H-u$ relationship. This increase of the initial stiffness can be seen at very small $\theta$ values (i.e., $5^{\circ}$ ). This initial stiffness is almost constant for all $\theta$ values greater than $0^{\circ}$. By increasing $u$ at the pile head, the initially increasing rate of $H$ starts to decrease at a specified point. However, this deviation from the initial stiffness of the lateral load component happens when the pile starts to fail in tension. This is observed for all piles regardless of the soil-pile flexibility $(L / T)$. This means that when the pile fails in tension, the $H-u$ relationship becomes nonlinear, which is the case of a rigid pile. From the $V-v$ relationships, it can be seen that pile tension capacity decreases when $\theta$ decreases. This reduction in pile tension capacity is significant at small $\theta$ values and up to almost $\theta=30^{\circ}$. For $\theta$ values larger than $30^{\circ}$, pile tension capacity is close to the case of pure vertical pullout loading.

For the F- $w$ relationship, pile response becomes stiffer by increasing $\theta$ from $0^{\circ}$ (pure lateral loading) to $90^{\circ}$ (pure tension loading). The total lateral ultimate capacity of the pile was taken as the total load corresponding to failure in tension. In all cases, it was 
Fig. 11. Load-displacement curves at pile head, case 4: (a) lateral component, $(b)$ vertical component, and $(c)$ total component.
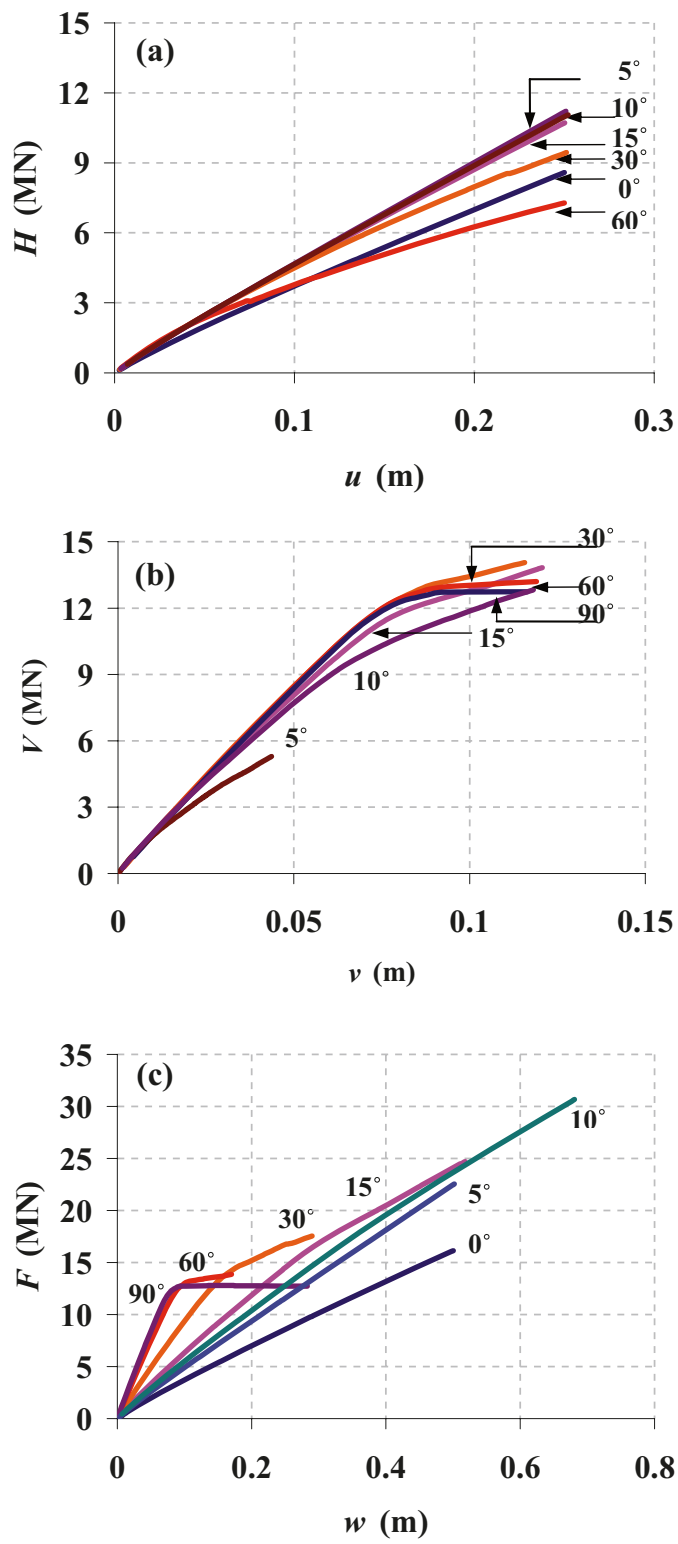

found that the pile reached the ultimate tension capacity before reaching the corresponding ultimate lateral capacity of a rigid pile with the same pile dimensions. The ultimate capacity of pile increases when $\theta$ decreases. The pile head deflection $(u)$ at the ultimate capacity increases when $\theta$ decreases. A design method to predict pile ultimate capacity will be discussed later.

Bending moment $(M)$ and pile lateral deflection $(u)$ profiles

Bending moment $(M)$ and pile lateral deflection $(u)$ profiles for case 4 are shown in Figs. $12 a$ and $12 b$, respectively. It is clear that the vertical pullout load component has a significant effect on $u$. Before failure in tension there is a reduction in $u$. The same pile loaded at different $\theta$ values larger than $0^{\circ}$ and at the same lateral load increment has the same $u$ and $M$ profiles before the pile fails in tension. What happens before tension failure is that the tension stresses in the pile lead to pile elongation and a decrease in pile curvature. When the pile-soil system starts to fail in tension the elongation reaches its ultimate value and the pile bending stiffness increases. The increase in pile bending stiffness corresponds to a reduction in $M$. This increase in pile bending stiffness
Fig. 12. Case 4, at lateral load increment $6000 \mathrm{kN}$ : (a) bending moment profile and $(b)$ lateral pile deflection profile.
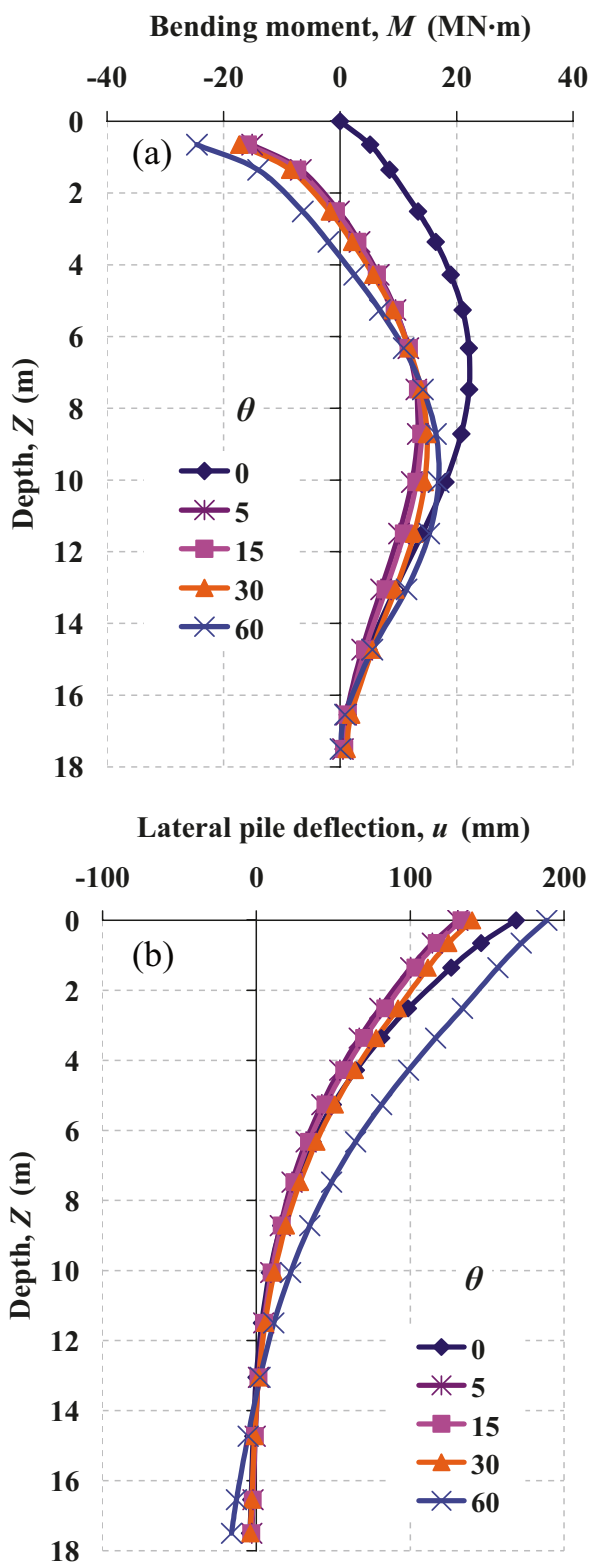

is more obvious for cases of $\theta=60^{\circ}$, where the pile reaches the ultimate capacity in tension at relatively small lateral load components. This is clear for cases of small $L / T$ values (cases 2 and 4), at which the pile rotates and behaves as a rigid pile after failing in tension. For other cases that have higher $L / T$ values, which means piles of higher flexibility, the curvature of the pile at shallow depths decreases and lateral deflection increases. However, the effect of the increase in pile bending stiffness decreases when the loading angle decreases, because by decreasing $\theta$ the pile reaches high curvature before failing in tension at larger $u$ values.

It can also be seen that after failing in tension, the maximum bending moment $\left(M_{\text {max }}\right)$ increases and goes deeper (case $4, \theta=60^{\circ}$ ). This occurs because as the soil fails in tension, the soil contribution to support the lateral forces decreases. When this soil contribution reduces, more load transfers to the pile. This can be seen as a decrease in soil-pile flexibility and the pile behaves as a rigid pile that rotates with less curvature, as shown in $u$ profiles.

For design purposes, the interest should be the conditions before reaching failure in tension. This means that before failure 
Fig. 13. Case 6, pure tension loading $\left(\theta=90^{\circ}\right)$ : (a) soil pressure and (b) soil shear stress.
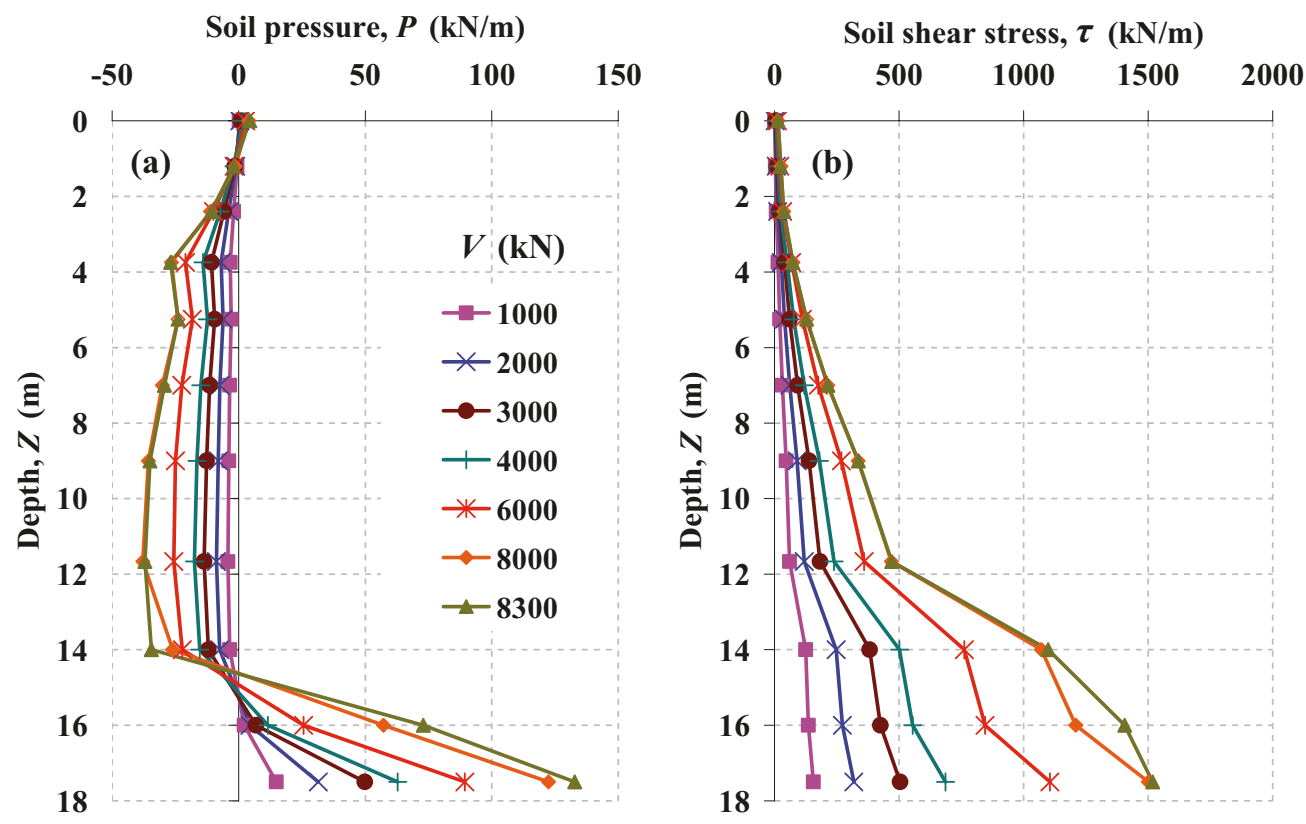

there is a constant reduction in pile lateral deflection for all $\theta$ values larger than $0^{\circ}$ regardless of the angle value. This reduction in pile lateral deflection causes a stiffer response of the pile as shown in load-displacement relationships and as will be discussed later.

\section{Soil pressure $(P)$ and shear stress $(\tau)$ profiles}

Soil pressure $(P)$ and soil shear stress $(\tau)$ profiles help to understand the interaction between lateral and vertical pullout loading. Figs. $13 a$ and $13 b$ show $P$ and $\tau$ distributions, respectively, for cases of pure tension loading. As the pile is subjected to a pure tension load, there will be a high resistance close to the pile tip where soil stresses are high due to pile driving. This tension loading process and the resistance at the pile tip will cause pile elongation. The elongation effect on $P$ distribution along the pile is clear in the figures. There is a reduction in $P$ along the pile length down to a depth close to the pile tip. As the pile elongates, the pile section contracts causing soil confining pressure to decrease. However, close to the pile tip, the developed resistance against pulling the pile out causes soil dilation and an increase in P. In Fig. 13, it can be seen that at high tension loads up to failure there is a significant reduction in soil stresses at the pile tip. This reduction happens when the pile starts to be pulled out and there is no further contact between the pile tip and the soil. In terms of $\tau$ distribution along the pile, it can be seen that it increases with depth. Also $\tau$ increases at a rate that increases with depth, which is similar to what was recommended by the ICP 2005 (Jardine at al. 2005) design method for offshore piles.

Soil pressure $(P)$ distribution is shown in Fig. 14 for different loading angles for case 4 . For all $\theta$ values greater than $0^{\circ}$ (pure lateral loading), there is a constant reduction in $P$ from that of the pure lateral loading case at shallow depths before the pile fails in tension. This reduction, which was also observed in bending moment profiles, is due to pile elongation as a result of the tension load component at the pile head as discussed before. At greater depths, there is also a reduction in $P$ at small $\theta$ values. However, by increasing $\theta$ the tension load component increases causing an increase in $P$ due to soil dilation, as discussed in the case of pure tension loading. When the pile fails in tension, no further soil shear stress will be developed. This will lead to a reduction in $P$ at shallow depths and an increase at greater depths as the resistance is going to deeper soil layers that can resist more. This is signifi-

Fig. 14. Soil pressure profile, case 4 at lateral load increment $4000 \mathrm{kN}$.

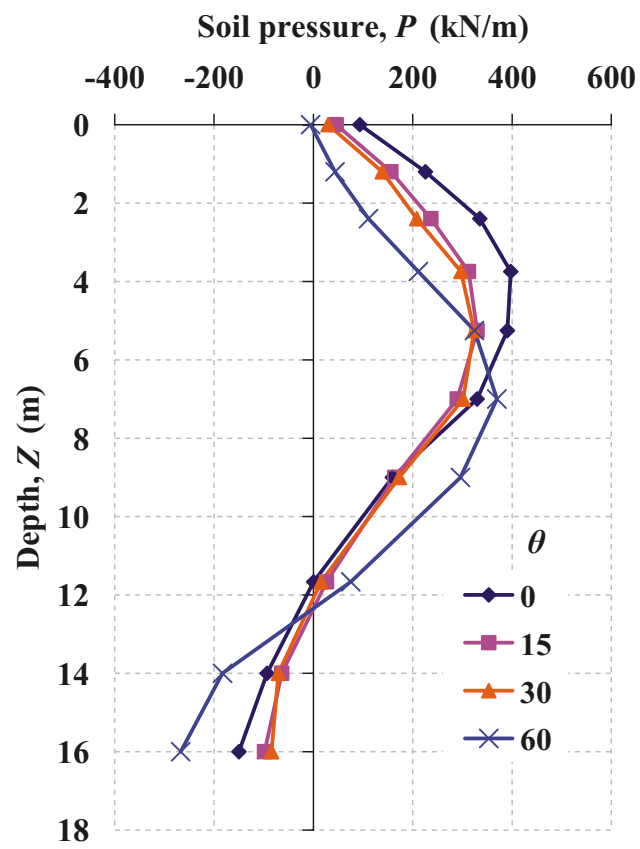

cant to what was observed in the $M$ profiles, where $M_{\max }$ moved to greater depths.

Soil shear stress $(\tau)$ distributions are shown in Fig. 15 for case 2 at different vertical pullout load increments. It can be seen that for small $\theta$ values, $\tau$ is the same at the same vertical pullout load increments. However, there is a small difference between small and large $\theta$ values at the same vertical load increment, especially for piles of less flexibility as shown in Fig. 15b. To mobilize the same vertical load increment, piles loaded at small $\theta$ values will be already subjected to higher $H$ and $u$ than that loaded at larger $\theta$ values. This higher $u$ will cause a reduction in the initial soil confining pressure on the back side of the loading direction. This will lead to less contact pressure on the back side, which causes 
Fig. 15. Soil shear stress profile at selected tension load increments, case $2:(a) V=2500 \mathrm{kN}$ and $(b) V=3500 \mathrm{kN}$.
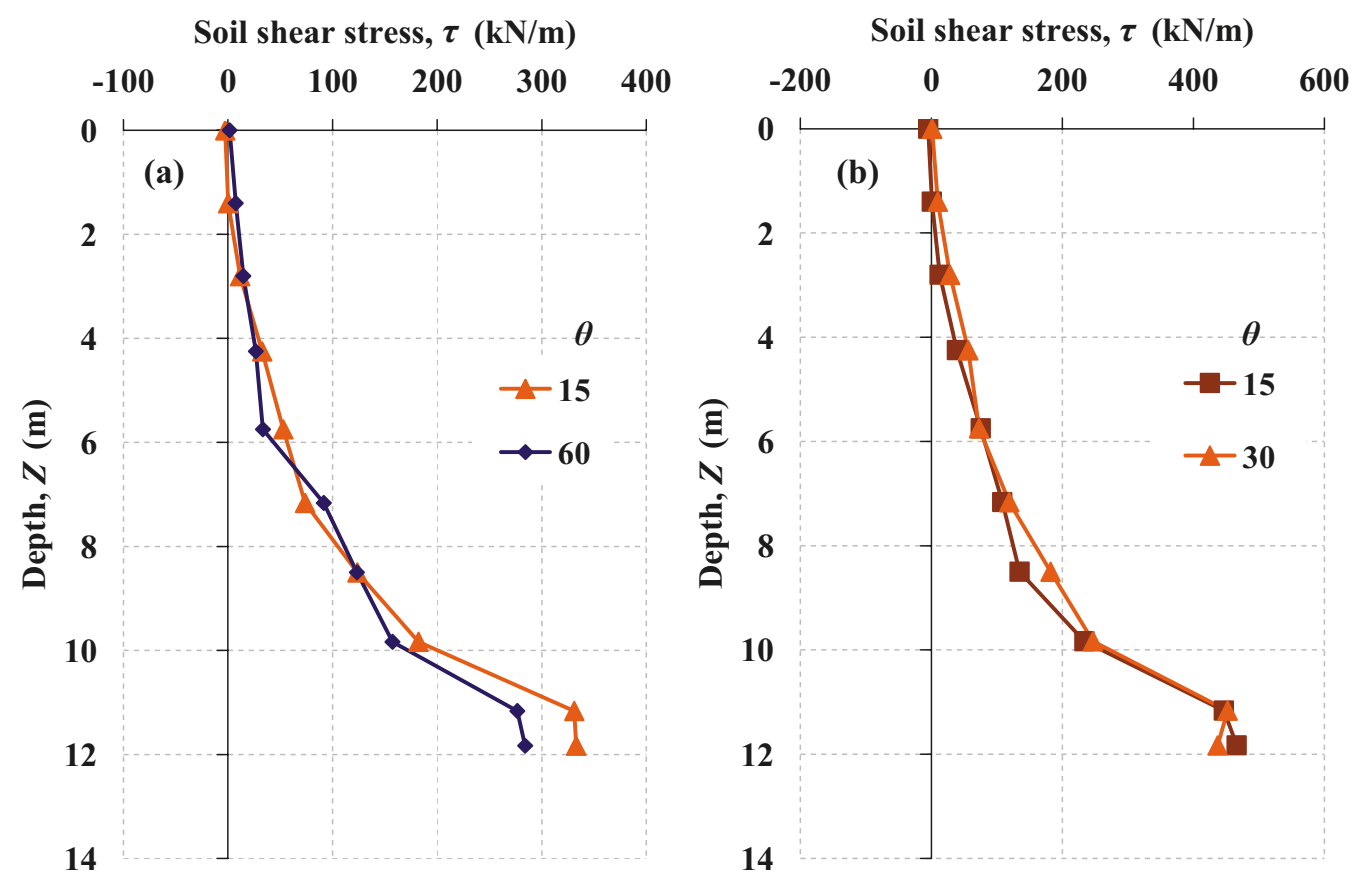

lower $\tau$ values at shallow depths. Close to the pile tip and when the pile is less flexible and tends to rotate, high $P$ values will be developed at the pile tip, which will be higher in the case of small $\theta$ values than large ones. The higher $P$ at the pile tip will cause higher $\tau$ to be developed in the case of small $\theta$ values than at large ones. For more flexible piles there will not be much difference at the pile tip for different $\theta$ values. However, the reduction in contact pressure on the back side at shallow depths will cause a reduction in $\tau$ values and consequently on the total pile tension capacity.

From the previous discussion on load-displacement relationships, pile lateral deflection $(u)$ profile, bending moment $(M)$ profile, and soil pressure $(P)$ and soil shear stress $(\tau)$ distributions, it can be concluded that there is a significant interaction between both lateral and vertical pullout loading cases. Such interaction should be considered in the design of offshore piles. Ignoring this interaction will lead to uneconomical design. In the following sections, a recommended design method for pile ultimate capacity and maximum bending moment will be presented.

\section{Proposed methods}

\section{Ultimate pile capacity}

The ultimate capacity of an offshore anchor pile subjected to inclined pullout load was obtained when the pile failed in tension. The ultimate tension pile capacity for different $\theta$ values was determined by plotting the load-displacement curves on log-log scale and picking the point of maximum curvature to be the failure load. The present design method can predict the ultimate pile capacity $\left(\mathrm{F}_{\mathrm{o}}\right)$ as

$$
\text { [11] } \quad F_{\mathrm{o}}=\sqrt{H_{\mathrm{f}}^{2}+V_{\mathrm{f}}^{2}}
$$

where $H_{\mathrm{f}}$ is the corresponding lateral load at tension failure and $V_{\mathrm{f}}$ is the failure tension load. By predicting both $H_{\mathrm{f}}$ and $V_{\mathrm{f}}$, the ultimate capacity of the pile $\left(F_{o}\right)$ can be obtained.

To predict $H_{\mathrm{f}}$, it was normalized to $H_{\mathrm{R}}$ (the ultimate lateral capacity of a rigid pile,which has the same pile diameter and length as the current cases) and plotted versus $\theta$ as shown in

Fig. 16. Normalized lateral load capacity $\left(H_{f} / H_{R}\right)$ versus loading angle $(\theta)$.

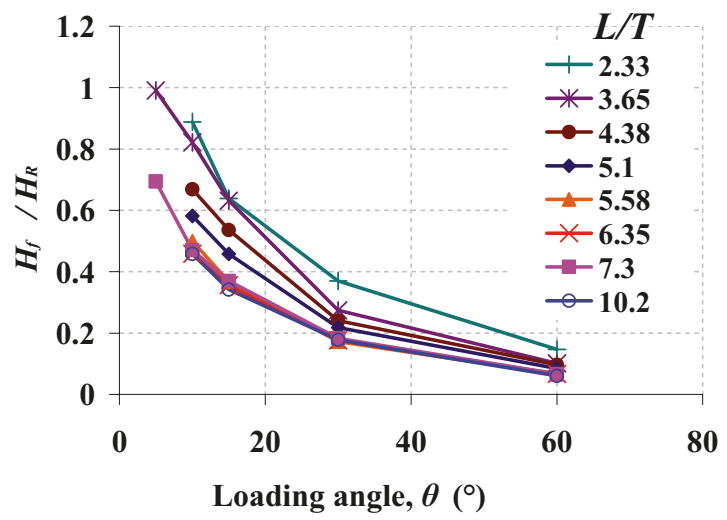

Fig. 16. The curves are shown for a wide range of $L / T$ values: from rigid the pile case to the pile of high flexibility. It can be seen from the figure that for all cases, $H_{f} / H_{R}$ decreases in an exponential decay manner when increasing $\theta$. However, the rate of decay decreases when increasing pile flexibility $(L / T)$. All curves were fitted to follow a decay exponential function

[12] $\quad H_{\mathrm{f}} / H_{\mathrm{R}}=\alpha_{\mathrm{H}} e^{-\beta_{\mathrm{H}} \theta}$

where $\alpha_{\mathrm{H}}$ and $\beta_{\mathrm{H}}$ are fitting parameters. It was found that the parameter $\beta_{\mathrm{H}}$ has almost a constant value of 0.046 . The parameter $\alpha_{\mathrm{H}}$ was found to be a function of pile flexibility $(\mathrm{L} / \mathrm{T})$. Figure 17 shows the change of $\alpha_{\mathrm{H}}$ with $\mathrm{L} / \mathrm{T}$. The plotted points were fitted as

[13] $\alpha_{\mathrm{H}}=\alpha_{\mathrm{Hmin}}+\frac{\alpha_{\mathrm{Hmax}}-\alpha_{\mathrm{Hmin}}}{1+\left(\frac{\mathrm{L} / \mathrm{T}}{4.67}\right)^{9.2}}$

where $\alpha_{\mathrm{Hmin}}=0.71$ and $\alpha_{\mathrm{Hmax}}=1.31$. 
Fig. 17. Relationship between the fitting parameter $\left(\alpha_{\mathrm{H}}\right)$ and pile flexibility ratio $(L / T)$.

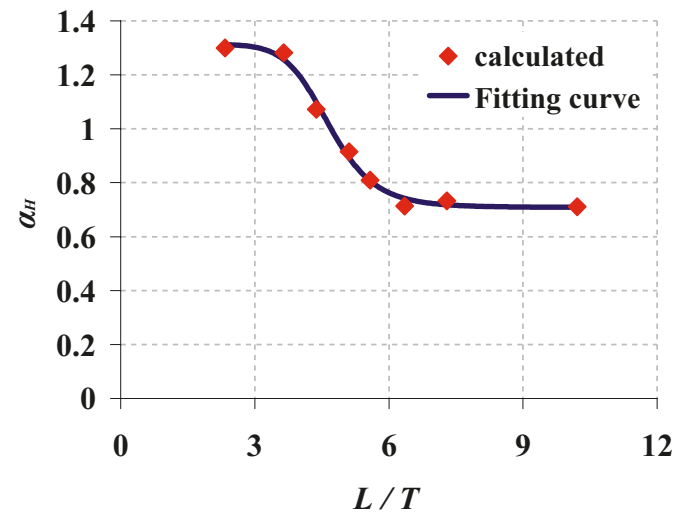

The ultimate lateral capacity of a rigid pile $\left(H_{R}\right)$ can be determined based on the equation recommended by Zhang et al. (2005). They suggested the following equation:

[14a] $\quad H_{\mathrm{R}}=0.3\left(\eta K_{\mathrm{P}}^{2}+\zeta K \tan \delta\right) \gamma x d(2.7 x-1.7 \mathrm{~L})$

where $K_{\mathrm{P}}$ is the passive earth pressure coefficient $\left(=\tan ^{2}\left(45^{\circ}+\right.\right.$ $/ 2)), K$ is the lateral earth pressure coefficient at rest $(=1-\sin )$, for circular piles $\eta$ and $\zeta$ are dimensionless factors equal to 0.8 and 1.0 , respectively, $\gamma$ is the unit weight of the soil, and $x$ is the depth to the point of rotation can be calculated as

$[14 b] \quad x=[-(0.567 \mathrm{~L}+2.7 e)$

$$
\left.+\left(5.307 L^{2}+7.29 e^{2}+10.541 e L\right)^{0.5}\right] / 2.1996
$$

By calculating the parameter $\alpha_{\mathrm{H}}$ using eq. [13] and using a value of 0.046 for the parameter $\beta_{\mathrm{H}}, H_{\mathrm{f}}$ can be determined.

Figure 18 shows the relationship between $\left(V_{\mathrm{u}} / V_{\mathrm{f}}\right)$ and $\theta$, where $V_{\mathrm{u}}$ is the ultimate tension capacity under the pure tension loading case $\left(\theta=90^{\circ}\right)$. It can be seen that all plotted cases follow the same trend. All data follow one function as

$$
V_{\mathrm{u}} / V_{\mathrm{f}}=1+8.8 e^{-0.33 \theta}
$$

It can be observed from Fig. 18 that a loading angle $(\theta)$ of almost $20^{\circ}$ is a critical angle below which the ultimate tension capacity decreases from the case of pure tension loading. Using eqs. [12] and [15] to calculate $H_{\mathrm{f}}$ and $V_{\mathrm{f}}$, respectively, $F_{\mathrm{o}}$ can be obtained using eq. [11] at different loading angles.

\section{Maximum bending moment}

As discussed before, for identical piles with the same lateral load increment at the pile head, there is a constant reduction in $M$ once $\theta$ becomes larger than $0^{\circ}$ (pure lateral loading). For all $\theta$ values larger than $0^{\circ}$, the $M$ profile is the same until the pile fails in tension. An example is shown in Fig. 19. In this figure, the relationship between $H_{n}$ and $M_{n-m a x}$ is linear in all cases. This is the same as what was observed from the centrifuge tests results. For the same pile, the relationship is the same for all $\theta$ values larger than $0^{\circ}$ (pure lateral loading) and before the pile fails in tension. The plotted data were fitted by a linear function as

$$
M_{\mathrm{n}-\max }=m H_{\mathrm{n}}
$$

where the slope $m$ can be considered as $m_{0}$ for pure lateral loading cases and $m_{\theta}$ for inclined pullout loading cases. The ratio of
Fig. 18. Normalized tension load capacity $\left(V_{\mathrm{u}} / V_{\mathrm{f}}\right)$ versus loading angle $(\theta)$.

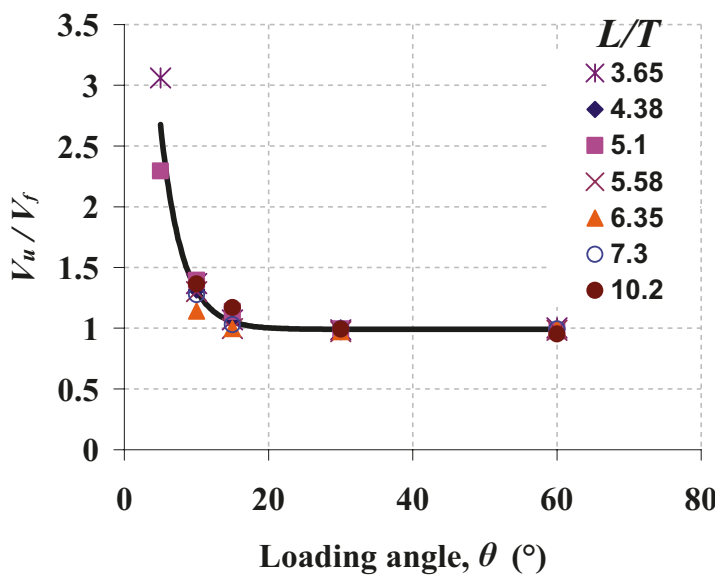

Fig. 19. Normalized horizontal load $\left(H_{n}\right)$ versus normalized maximum bending moment $\left(M_{\mathrm{n}-\mathrm{max}}\right)$ for all tests, case 6 .

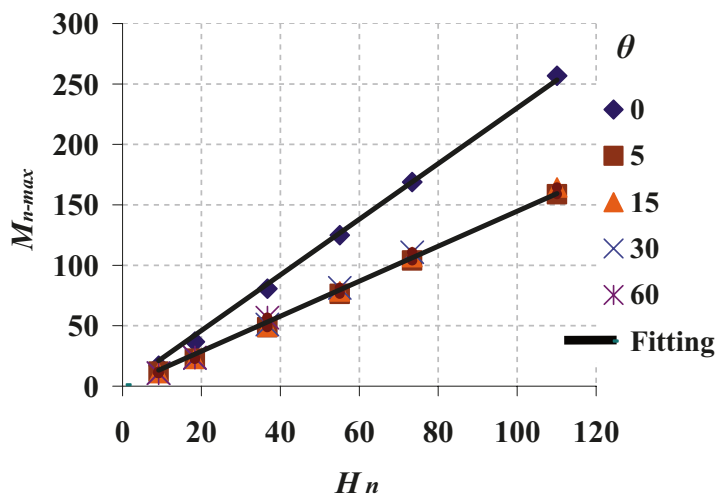

Fig. 20. Maximum bending moment ratio $\left(m_{0} / m_{\theta}\right)$ versus pile flexibility ratio $(L / T)$.

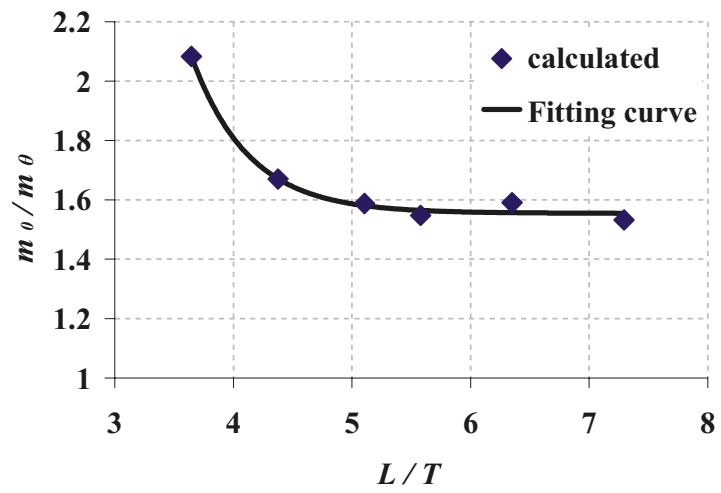

$\left(m_{0} / m_{\theta}\right)$ for different cases is plotted versus $(L / T)$ in Fig. 20. The plotted data were fitted as

$$
m_{0} / m_{\theta}=1.55+1029 e^{-2.077(\mathrm{~L} / \mathrm{T})}
$$

Using eq. [17], $M_{\max }$ of offshore anchor piles subjected to inclined pullout loading can be predicted at any stage during loading up to tension failure. The bending moment of the pile $(M)$ under pure lateral loading is needed to use eq. [17]. This $M$ can be calculated using certain available codes or methods that are being used in the industry, such as LPile software. It should be noted 
that $M_{\max }$ that can be predicted from the current proposed method is the positive bending moment. In most cases the maximum negative bending moment close to pile head is less than or equal to the maximum positive bending moment before the pile fails in tension. The maximum negative bending moment should be less than what was observed in the current study. An offshore anchor pile is usually loaded at a pad eye, and the pile wall thickness is larger at pad eye locations. This means that the pile stiffness at the loading level is higher than pile stiffness at any other location along the pile. Also, the stress localization at the pile head where the displacement is applied in the FEM could cause some increase in the maximum negative stress at the pile head.

\section{Conclusion}

In this paper, the calibrated FEM using the centrifuge tests results was used to perform a parametric study. In the parametric study, all cases were carried out by pulling out the pile at the ground surface.

It was found that pile response becomes stiffer by increasing loading angle $(\theta)$ from $0^{\circ}$ (pure lateral loading) to $90^{\circ}$ (pure tension loading). The pile ultimate capacity $\left(\mathrm{F}_{\mathrm{o}}\right)$ was taken as the total load corresponding to failure in tension. This ultimate capacity and the corresponding pile head displacement increase when loading angle decreases. There is a significant interaction between the lateral and tension loadings. The tension load component causes pile elongation and a corresponding radial cross-section contraction. This increases pile bending stiffness and decreases soil pressure $(P)$ around the pile except at depths close to the pile tip. As the soil pressure $(P)$ close to pile tip is high due to pile driving, $P$ increases when $\theta$ increases, which means an increase in the tension load component. When the pile fails in tension, no more soil shear stress $(\tau)$ will be developed. The soil contribution to support the lateral forces decreases. When this soil contribution reduces, more load transfers to the pile. This leads to a reduction in $P$ at shallow depths and an increase at greater depths as the resistance is going to deeper soil layers that can resist more. This is similar to what was observed in bending moment $(M)$ profiles where maximum bending moment $\left(M_{\max }\right)$ moved to greater depths.

Two design methods were proposed. The first method predicts the pile ultimate total capacity $\left(F_{o}\right)$. The total capacity of the pile can be obtained using eq. [11] by determining both the tension pile capacity and the corresponding lateral capacity of the pile at failure in tension. The tension capacity of the pile at any $\theta$ value can be determined using eq. [14]. The corresponding pile lateral capacity to tension failure $\left(H_{\mathrm{f}}\right)$ at different $\theta$ values can be determined using eq. [12], which is a function of pile flexibility $(\mathrm{L} / \mathrm{T})$ and the ultimate lateral capacity of the rigid pile $\left(H_{\mathrm{R}}\right)$. The second method predicts the maximum positive bending moment $\left(M_{\text {max }}\right)$ of a pile subjected to inclined pullout loading. The prediction depends on the pile flexibility $(\mathrm{L} / \mathrm{T})$ and the maximum bending moment of the same pile at pure lateral loading.

It should be noted that the available design methods are limited to pipe piles in dense sand. Other soil types and nonhomogeneous soil should be considered in future research.

\section{References}

Achmus, M., Abdel-Rahman, K., and Thieken, K. 2009. Numerical study of the effect of combined loading on the behavior of piles in sand. International Symposium on Computational Geomechanics, (ComGeo I), 29 April -1 May 2009. Juan-les-Pins, France.
API. 2000. Recommended practice for planning, designing and constructing fixed offshore platforms-working stress design. RP2A-WSD 21st ed. American Petroleum Institute.

Baldi, G., Bellotti, R., Ghionna, V., Jamiolkowski, M., and Pasqualini, E. 1982. Design parameters for sands from CPT. In Proceedings of the Second European Symposium on Penetration Testing, ESOPT II, Amsterdam, May 1982. Vol. 2, pp. 425-438.

Bolton, M.D. 1986. The strength and dilatancy of sands. Géotechnique, 36(1): 65-78. doi:10.1680/geot.1986.36.1.65.

Bolton, M.D., and Gui, M.W. 1993. The study of relative density and boundary effects for cone penetration tests in centrifuge. Technical Report (CUED/ D-SOILS/TR256)

Broms, B.B. 1964. Lateral resistance of piles in cohesionless soils. Journal of Soil Mechanics and Foundations Division, ASCE, 90(SM3): 123-156.

Chakrabortty, P. 2008. Seismic liquefaction of heterogeneous soil: mechanism and effects on structural response. Ph.D. thesis, Memorial University of Newfoundland, St. John's, N.L.

De Nicola, A., and Randolph, M.F. 1993. Tensile and compressive shaft capacity of piles in sand. Journal of Geotechnical Engineering, 119(12): 1952-1973. doi:10. 1061/(ASCE)0733-9410(1993)119:12(1952).

De Nicola, A., and Randolph, M.F. 1999. Centrifuge modelling of pipe piles in sand under axial loads. Géotechnique, 49(3): 295-318. doi:10.1680/geot.1999. 49.3.295.

Dyson, G.J., and Randolph, M.F. 2001. Monotonic lateral loading of piles in calcareous sand. Journal of Geotechnical and Geoenvironmental Engineering, 127(4): 346-352. doi:10.1061/(ASCE)1090-0241(2001)127:4(346).

Ferguson, K.A., and Ko, H.Y. 1984. Application of centrifugal modelling to cone penetrometer technology. International Symposium on Application of Centrifuge Modelling to Geotechnical Design, Manchester.

Hibbitt, Karlsson, and Sorensen, Inc. 1998. ABAQUS: Standard user manuals. Hibbitt, Karlsson, and Sorensen, Inc., Pawtucket, USA.

Jardine, R.J., Chow, F.C., Overy, R.F., and Standing, J.R. 2005. ICP design methods for driven piles in sands and clays. Thomas Telford, London.

Lancelot, L., Shahrour, I., and Al Mahmoud, M. 2006. Failure and dilatancy properties of sand at relatively low stresses. Journal of Engineering Mechanics, 132(12): 1396-1399. doi:10.1061/(ASCE)0733-9399(2006)132:12(1396).

Meyerhof, G.G. 1995. Standard penetration tests and pile behaviour under lateral loads in cohesionless soils. Canadian Geotechnical Journal, 32(5): 913916. doi:10.1139/t95-088.

Puech, A., and Foray, P. 2002. Refined model for interpreting shallow penetration CPTs in sands. Offshore Technology Conference, OTC 14275

Ramadan, M.I. 2011. Physical and numerical modeling of offshore anchor piles under mooring forces. Ph.D. thesis, Memorial University of Newfoundland, St. John's, N.L.

Randolph, M.F., Cassidy, M.J., Gourvenec, S., and Erbrich, C.J. 2005. Challenges of offshore geotechnical engineering, State of the art paper. Proceedings of International Conference on Soil Mechanics and Foundation Engineering, Osaka, Japan.

Robertson, P.K. 2010. Estimating in-situ state parameter and friction angle in sandy soils from CPT. CPT'10, 2nd International Symposium on Cone Penetration Testing, Calif.

Robertson, P.K., and Campanella, R.G. 1983. Interpretation of cone penetration tests. Part I. Sand. Canadian Geotechnical Journal, 20(4): 718-733. doi:10.1139/ t83-078.

Schmertmann, J.H. 1978. Guidelines for cone penetration tests, performance and design. US Federal Highway Administration, Washington, D.C., Report FHWA-TS-78-209.

Thompson, G.R., and Long, L.G. 1989. Hibernia geotechnical investigation and site characterization. Canadian Geotechnical Journal, 26(4): 653-678. doi: 10.1139/t89-078.

Turner, J.P., and Kulhawy, F.H. 1994. Physical modeling of drilled shaft side resistance in sand. Geotechnical Testing Journal, 17(3): 282-290. doi:10.1520/ GTJ10103J.

Vaid, Y.P., Stedman, J.D., and Sivathayalan, S. 2001. Confining stress and static shear effects in cyclic liquefaction. Canadian Geotechnical Journal, 38(3): 580-591. doi:10.1139/t00-120.

Zhang, L., Silva, F., and Grismala, R. 2005. Ultimate lateral resistance to piles in cohesionless soils. Journal of Geotechnical and Geoenvironmental Engineering, 131(1): 78-83. doi:10.1061/(ASCE)1090-0241(2005)131:1(78).

Zhu, F. 1998. Centrifuge modeling and numerical analysis of bearing capacity of ring foundations on sand. Ph.D. thesis, Memorial University of Newfoundland, St. John's, N.L. 